\title{
Torque Ripple Minimization of a Switched Reluctance Motor using a Torque Sharing Function based on the Overlap Control Technique
}

\author{
Hady Abdel Maksoud \\ Department of Electrical Engineering \\ Menoufia University \\ Shebin El-Koum, Egypt \\ thady_elgendy@yahoo.com
}

\begin{abstract}
The torque ripple produced in a switched reluctance motor (SRM) can be seen as one its major drawbacks. It occurs mainly due to the sequential switching of the motor phases and changes in the length of the air gap. The torque sharing functions (TSFs) are the more effective and favorable techniques developed to reduce the torque ripple in SRMs. However, the time responses of instantaneous torque for incoming and outgoing phases during commutation period (CP) are different. In addition, with increasing motor speed the $C P$ decreases and the torque response of the outgoing phase oversteps it. In this paper, a modified torque sharing function based on the change of the overlap angle during the commutation process depending on the motor speed is presented. In the designed control algorithm of the TSFs, the motor speed is has become an input besides the rotor position and the torque command. The commutation time is precisely adjusted enough for the commutating process. The proposed method gives good results in a wide speed range. To deduce the magnetic characteristics of the SRM, finite element analysis (FEA) is applied and a look-up table model is derived. The effectiveness and robustness of the proposed control technique are exhibited in the simulation results.
\end{abstract}

Keywords-switched reluctance motor; torque ripple minimization; torque sharing function (TSF); commutation period (CP)

\section{INTRODUCTION}

Torque ripple is a common problem in various electrical machines like Permanent Magnets (PMs) and Switched Reluctance Motors (SRMs) [1-3]. In the SRM, high torque ripple is produced as a result of its construction and commutation process [4-5]. The pulsating torque oscillations during the phase commutation period occur when the produced torque is being switched between two adjacent phases. This higher torque ripple produces undesirable noise and oscillations. Hence, control of torque ripple reduction is a challenging search area [6-7]. Many methods have been used to reduce the torque ripple either as a part of the SRM design process or by using alternative control strategies [8-10]. Torque sharing function can be considered one of the most effective methodologies used to reduce torque ripple in SRM. It depends on organizing incoming and outgoing phase torque so that the resultant torque is kept constant during the commutation between phases [11-13]. However, at the beginning of the commutation, the instant torque generated by the incoming phase is near the position of the unaligned rotor where the inductance has its minimum value. While at the end of the commutation, the instant torque resulting from the outgoing phase is near to the aligned rotor position where the phase inductance reaches its top value, and the torque will not attain its reference rapidly due to the tail of current. In addition, increasing speed will also produce impairment of torque tracking performance [14-16]. An online compensating of the TSF which applies positive compensation at the beginning of the commutation for outgoing phase and negative compensation at the end of the commutation for the incoming phase is presented in [16]. The torque ripples rose with increasing motor speed. Another torque ripple compensation technique based on TSF strategy is introduced in [17], however the result torque has still relatively large ripples. An improved online TSF based on optimization of the control parameters is discussed in [18], but the results are given at only one speed. In [19], a neuro-fuzzy compensator is used to shape the motor current by adding a compensating signal to the output of the controller. A modified TSF is presented in [20] where the incoming torque phase has been compensated by the outgoing phase while the supplemental outgoing torque phase has reduced the reference torque of the incoming phase. A unified control for minimizing torque ripple in SRM is proposed in [21], where direct instantaneous torque control and current control are implemented. In [22], torque sharing function based fuzzy logic control (FLC) is developed for torque ripple reduction. However, using the sliding mode and look-up table model besides FLC made the system more complicated.

In this paper, a torque ripple minimization method using a TSF based overlap control technique is proposed. A simple and convenient control method to make online modifications of the overlap period for the torque sharing function is presented and a look-up table model based FEA for the SRM is derived. The effectiveness and robustness of the proposed method are verified by simulations at different motor speeds 


\section{MODELING OF SWITCHED RELUCTANCE MOTOR}

The magnetic circuits of the motor have been analyzed by using a two-dimensional Finite Element Method (FEM). Based on (1) and (2), the analysis of the magnetic circuit at different rotor position angles and phase excitation currents is achieved. The solution started from the unaligned $\left(\theta=0^{0}\right)$ up to the aligned position $\left(\theta=45^{\circ}\right)$ with different values of phase current. The flux distributions and the flux linkage-current curves at different rotor position angles are obtained as shown in Figures $1-3$.

$$
\begin{aligned}
\varphi(\theta, \mathrm{i}) & =\int_{\mathrm{S}} \overrightarrow{\mathrm{B}} \cdot \mathrm{d} \overrightarrow{\mathrm{S}}=\int_{\mathrm{S}}(\tilde{\mathrm{N}} \times \overrightarrow{\mathrm{A}}) \cdot \mathrm{d} \overrightarrow{\mathrm{S}}=\oint_{1} \overrightarrow{\mathrm{A}} \cdot \mathrm{d} \overrightarrow{\mathrm{l}} \\
& =\mathrm{L}\left[\mathrm{A}\left(\mathrm{x}_{\mathrm{j}}, \mathrm{y}_{\mathrm{j}}\right)-\mathrm{A}\left(-\mathrm{x}_{\mathrm{j}}, \mathrm{y}_{\mathrm{j}}\right)\right]
\end{aligned}
$$

where $\mathrm{L}$ is the length of the motor, and $( \pm \mathrm{x}, \mathrm{y})$ are points in the winding area. Assuming the overall winding turns per phase $\mathrm{T}_{\mathrm{ph}}$, (1) can be written as:

$$
\psi(\theta, \mathrm{i})=\frac{\mathrm{LT}_{\mathrm{ph}}}{\mathrm{S}_{\mathrm{w}}}\left[\int_{\mathrm{S}_{\mathrm{w} 1}} \mathrm{~A}(\mathrm{x}, \mathrm{y}) \mathrm{dS}_{\mathrm{w} 1}-\int_{\mathrm{S}_{\mathrm{w} 2}} \mathrm{~A}(\mathrm{x}, \mathrm{y}) \mathrm{dS}_{\mathrm{w} 2}\right]
$$

where $\mathrm{S}_{\mathrm{w}}$ is the winding cross section area, $\mathrm{S}_{\mathrm{w} 1}$ and $\mathrm{S}_{\mathrm{w} 2}$ characterize the sides of the winding area.

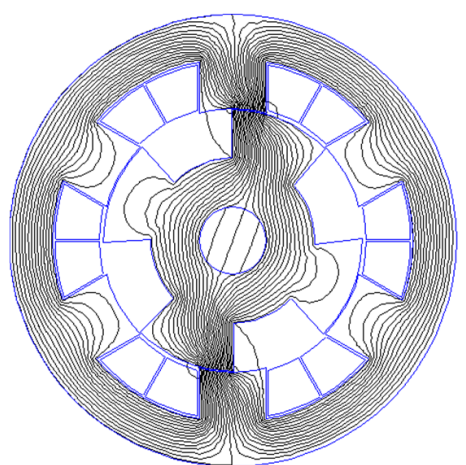

Fig. 1. Flux distribution for 3-phase 6/4 doubly-salient structure

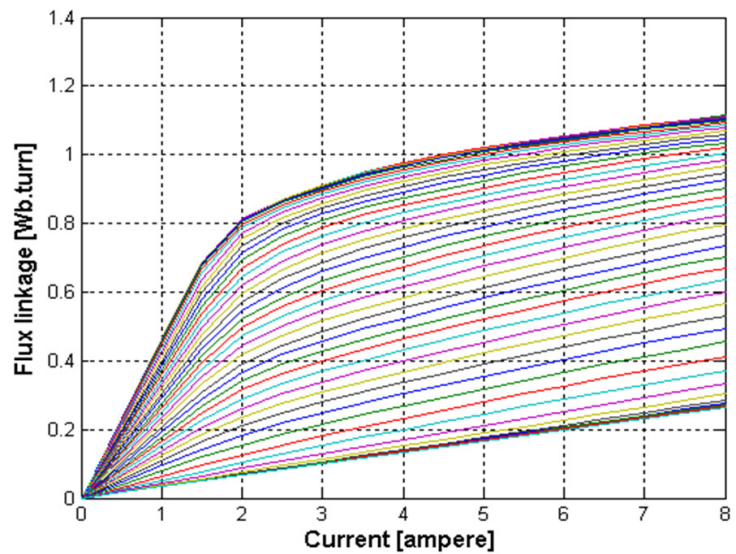

Fig. 2. $\psi$-i curves for 3-phase 6/4 doubly-salient structure at different rotor position angles

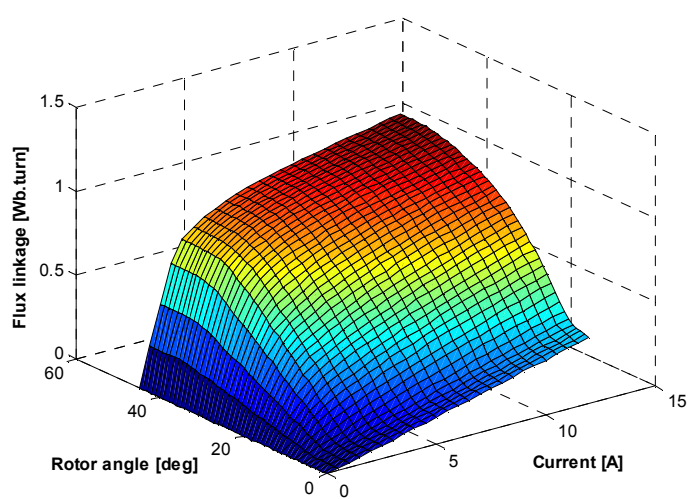

Fig. 3. Magnetic characteristics of 3-phase 6/4 doubly-salient structure

\section{A. Static Model}

The voltage equation for any phase $\mathrm{k}$ at the rotor position $\theta_{\mathrm{k}}$ can be represented as:

$$
\mathrm{V}_{\mathrm{k}}\left(\theta_{\mathrm{k}}\right)=\mathrm{R}_{\mathrm{k}} \mathrm{i}_{\mathrm{k}}+\frac{\mathrm{d} \psi_{\mathrm{k}}\left(\theta_{\mathrm{k}}, \mathrm{i}_{\mathrm{k}}\right)}{\mathrm{dt}} \quad \mathrm{k}=1,2,3
$$

where $R$ is the phase resistance and $V_{k}\left(\theta_{k}\right)$ is the voltage applied to the phase winding $\mathrm{k}$. The FEA curves are reorganized and stored in the form of $\mathrm{i}(\theta, \psi)$ look-up tables. By applying the numerical integration process to (3), the flux linkage for different phases is attained. The time stepping procedure is used for achieving the produced torque. The numerical integration of the $\psi(\theta, \mathrm{i})$ with respect to phase current is calculated for each step to get the phase co-energy:

$$
\mathrm{W}_{\mathrm{k}}\left(\theta_{\mathrm{k}}, \mathrm{i}_{\mathrm{k}}\right)=\int_{0}^{\mathrm{i}} \psi_{\mathrm{k}}\left(\theta_{\mathrm{k}}, \mathrm{i}_{\mathrm{k}}\right) \mathrm{di}_{\mathrm{k}}
$$

The produced torque can be calculated by differentiating the co-energy $\mathrm{W}_{\mathrm{k}}\left(\theta_{\mathrm{k}}, \mathrm{i}_{\mathrm{k}}\right)$ to the rotor position $\theta_{\mathrm{k}}$ :

$$
\mathrm{T}_{\mathrm{k}}\left(\theta_{\mathrm{k}}, \mathrm{i}_{\mathrm{k}}\right)=\frac{\partial \mathrm{W}_{\mathrm{k}}\left(\theta_{\mathrm{k}}, \mathrm{i}_{\mathrm{k}}\right)}{\partial \theta_{\mathrm{k}}}
$$

From the sum of the instantaneous developed torque, the total torque can be determined as:

$$
\mathrm{T}=\sum_{\mathrm{k}=1}^{3} \mathrm{~T}_{\mathrm{k}}\left(\theta_{\mathrm{k}}, \mathrm{i}_{\mathrm{k}}\right)
$$

\section{B. Dynamic Model}

The dynamic model equations of for SRM can be derived as:

$$
\begin{gathered}
\frac{d \psi_{k}\left(\theta_{\mathrm{k}}, \mathrm{i}_{\mathrm{k}}\right)}{\mathrm{dt}}=\mathrm{V}_{\mathrm{k}}-\mathrm{R}_{\mathrm{k}} \mathrm{i}_{\mathrm{k}} \\
\frac{\mathrm{d} \theta}{\mathrm{dt}}=\omega \\
\frac{\mathrm{d} \omega}{\mathrm{dt}}=\frac{1}{\mathrm{~J}}\left(\sum_{\mathrm{k}=1}^{3} \mathrm{~T}_{\mathrm{k}}\left(\theta_{\mathrm{k}}, \mathrm{i}_{\mathrm{k}}\right)-\mathrm{T}_{\mathrm{L}}-\mathrm{B} \omega\right)
\end{gathered}
$$

where $\omega, \mathrm{J}, \mathrm{B}$ are rotor speed, moment of inertia and viscous damping constant respectively. 


\section{TORQUE SHARING STRATEGY}

Torque sharing function is an effective methodology to perform SRM control, in which reference torques for different phases are specified supposing that the summing torque remains at a constant level [14]. In the commutation region, the incoming and outgoing phases share the output torque producing in order to keep it constant. The TSF can be formulated analytically as in (10) by choosing the functions $f_{\text {rise }}$ and $\mathrm{f}_{\text {fall. }}$.

$$
\mathrm{T}_{\text {ref }}(\mathrm{k})=\left\{\begin{array}{cc}
0 & 0 \leq \theta<\theta_{\text {on }} \\
\mathrm{T}_{\mathrm{d}} \mathrm{f}_{\text {rise }}(\theta) & \theta_{\text {on }} \leq \theta<\theta_{\text {on }}+\theta_{\text {ov }} \\
\mathrm{T}_{\mathrm{d}} & \theta_{\text {on }}+\theta_{\text {ov }} \leq \theta<\theta_{\text {off }} \\
\mathrm{T}_{\mathrm{d}} \mathrm{f}_{\text {fall }}(\theta) & \theta_{\text {off }} \leq \theta<\theta_{\text {off }}+\theta_{\text {ov }} \\
0 & \theta_{\text {off }}+\theta_{\text {ov }} \leq \theta<\theta_{\mathrm{p}}
\end{array}\right.
$$

where $T_{\text {ref }}(k)$ is the reference torque for phase $k, T_{d}$ is the overall torque command, $f_{\text {rise }}(\theta)$ is the rising TSF for the incoming phase, $f_{\text {fall }}(\theta)$ is the decreasing TSF for the outgoing phase, and $\theta_{\text {on }}, \theta_{\text {off, }}, \theta_{\text {ov }}, \theta_{\mathrm{p}}$ are turn-on angle, turn-off angle, overlapping angle, and rotor pole pitch, respectively. Figure 4 shows the typical profiles of the reference torque with a linear TSF method. It can be observed that the overlap angle (commutation angle) is a constant for the specified TSF. This method is more efficient when the motor operates at constant speed.

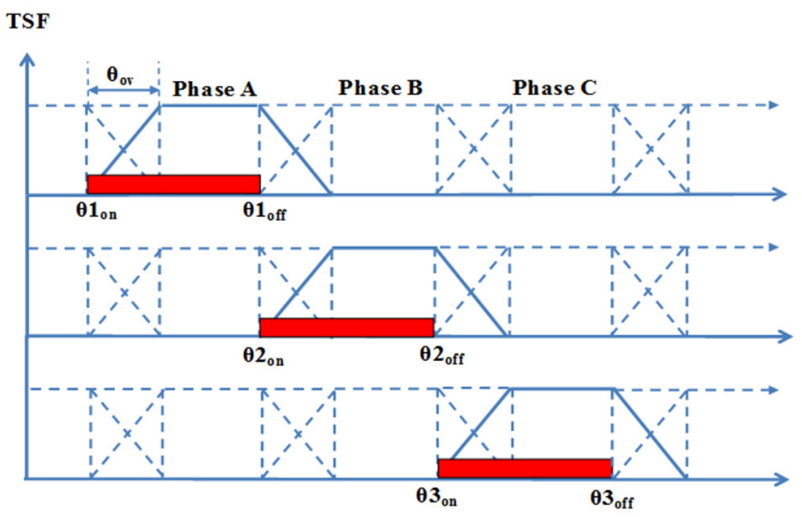

Fig. 4. The typical profiles of reference torque with a linear TSF method

Figure 5 shows the block diagram of the torque ripple minimization scheme based on TSF strategy. The output of TSF (the reference torque signal) depends only on the torque command $\mathrm{T}_{\mathrm{d}}$ and rotor position $\theta$. The reference torque converts to a reference current using torque current converter. The current control becomes difficult when the motor speed is changed. The actual motor current fails to track its reference current because the Commutation Period (CP) decreases with increasing speed and the overlap angle is fixing as shown in Figure 6. Likewise, the CP becomes bigger than the required value when the motor is operated at low speeds as presented in Figure 7 . In both cases the resultant torque has high torque ripples.

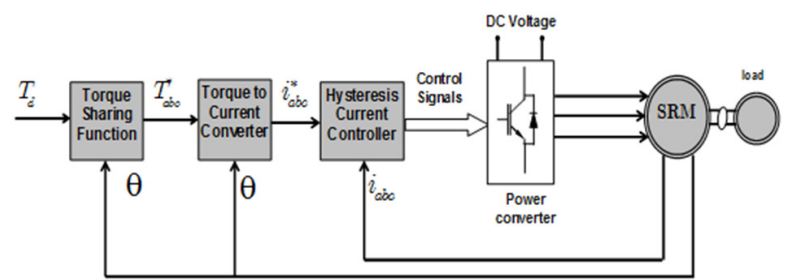

Fig. 5. Torque ripple minimization scheme based on TSF strategy
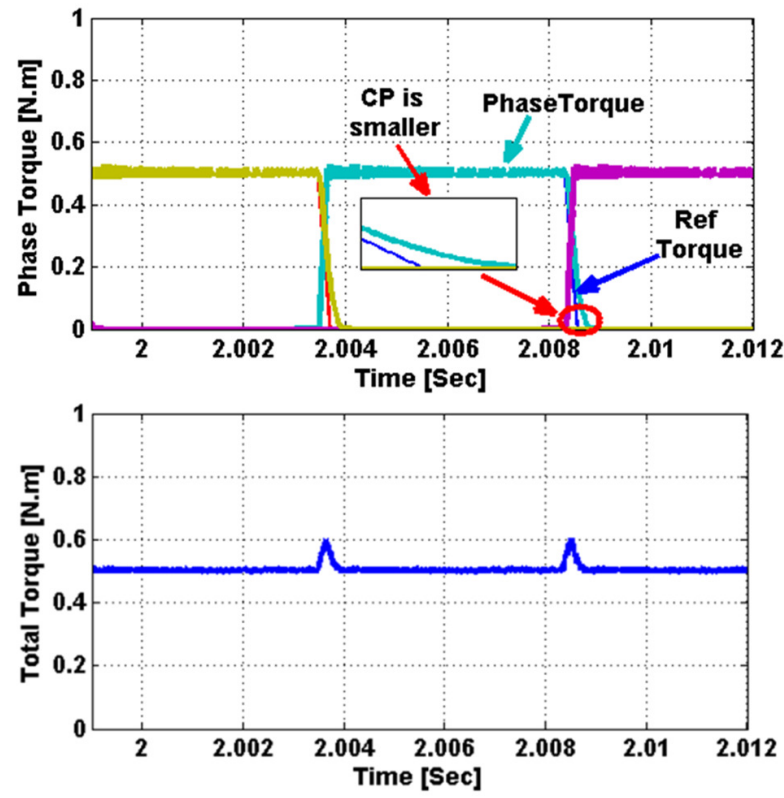

Fig. 6. The change in the torque at high speed using the conventional TSF
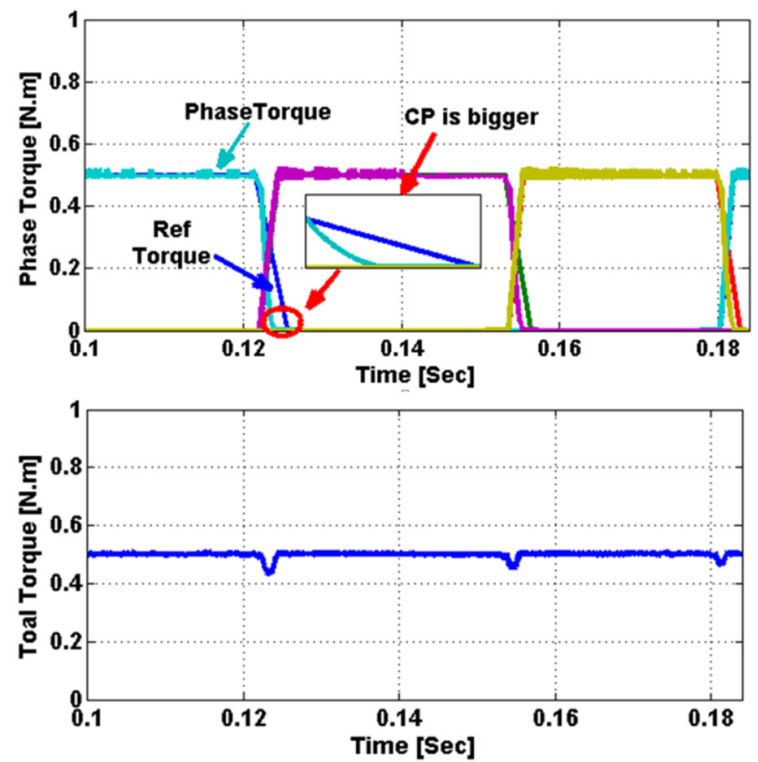

Fig. 7. The change in the torque at low speed during starting using the conventional TSF 


\section{PROPOSED TSF OVERLAP CONTROL TECHNIQUE}

As mentioned above, the classic TSF may make the undesirable torque ripple when the motor speed is changed. The proposed TSF technique is developed for compensating the torque ripple at different speeds. The principle of the proposed method is shown in Figure 8. It can be noted that the output of TSF not only depends on the torque command $T_{d}$ and rotor position $\theta$ but also on the motor speed $\omega$. Attendance of speed as one of the TSF inputs is intended to control continuously the overlap angle with changing motor speed. By this method, the overlap angle will be precise enough for commutation process. In other words, variations in the motor speed have no effect on the effectiveness of this algorithm.

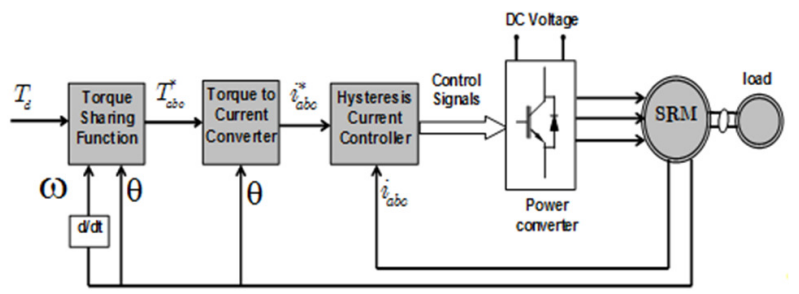

Fig. 8. Torque ripple minimization scheme based the proposed technique

The proposed TSF can be expressed by:

$$
\mathrm{T}_{\text {ref }}(\mathrm{k})=\left\{\begin{array}{cc}
0 & 0 \leq \theta<\theta_{\text {on }} \\
\mathrm{T}_{\mathrm{d}} \mathrm{f}_{\text {rise }}(\theta) & \theta_{\text {on }} \leq \theta<\theta_{\text {on }}+\theta_{\text {cov }} \\
\mathrm{T}_{\mathrm{d}} & \theta_{\text {on }}+\theta_{\text {cov }} \leq \theta<\theta_{\text {off }} \\
\mathrm{T}_{\mathrm{d}} \mathrm{f}_{\text {fall }}(\theta) & \theta_{\text {off }} \leq \theta<\theta_{\text {off }}+\theta_{\text {cov }} \\
0 & \theta_{\text {off }}+\theta_{\text {cov }} \leq \theta<\theta_{\mathrm{p}}
\end{array}\right.
$$

where $\theta_{\text {cov }}$ is the controlled overlap angle depending on the motor speed. After the torque reference is defined by the proposed TSF, the different phase torque references are transformed into the current references based on torquecurrent-position characteristics that are obtained from FEA. Then the hysteresis current controller is applied to regulate the feedback current to follow its reference current.

\section{SIMULATION RESULTS AND COMPARISON}

According to the schematic diagram of the proposed TSF mentioned above, a simulation model based on $200 \mathrm{~W}, 6 / 4$ SRM is developed in MATLAB/Simulink. It is designed as a multilayer program with a graphic interface containing a main system (Figure 9) calling many interconnected subsystems. The three consisting subsystems are the proposed TSF, a torque to current converter and the SRM. The Simulink model is built based on a fixed step with 0.00005 sample time. In order to compare the proposed technique with the conventional linear TSF, the turn on angle, the turn off angle and the torque command in the two techniques are equal to $8^{\circ}, 38^{\circ}$, and 0.5 N.m respectively. Furthermore, the overlap angle in the conventional TSF is kept constant at $2.5^{\circ}$ but in the proposed model is varied with the motor speed. The two techniques are examined and compared at different motor speeds.

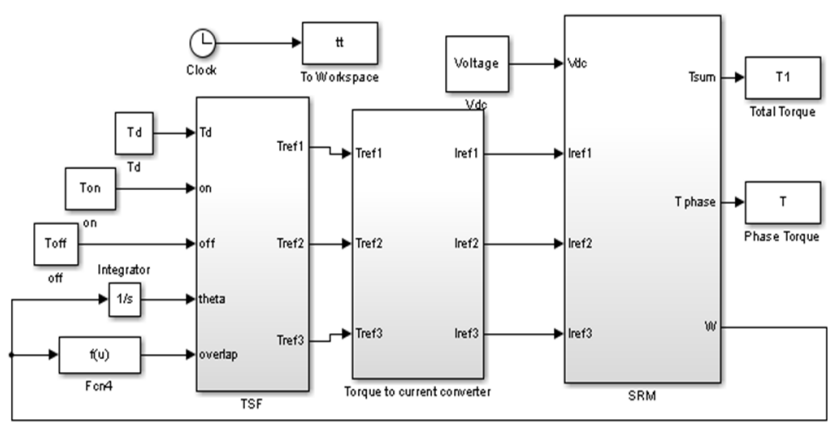

Fig. 9. Simulink model of the proposed TSF for SRM

\section{A. Starting Operation}

The starting of the motor is the best example to study the effect of speed on the commutation period. During starting the speed increases and the CP decreases with the same overlap angle which is constant at $2.5^{\circ}$. Figure 10 shows the change in the torque during start with the use of the conventional TSF. It can be observed that the torque ripple is larger in the first torque pulse when the $\mathrm{CP}$ is bigger than the period and the current needs to decay to zero. With increasing motor speed the $\mathrm{CP}$ decreases and torque ripples decay until the motor speed reaches its rated value.
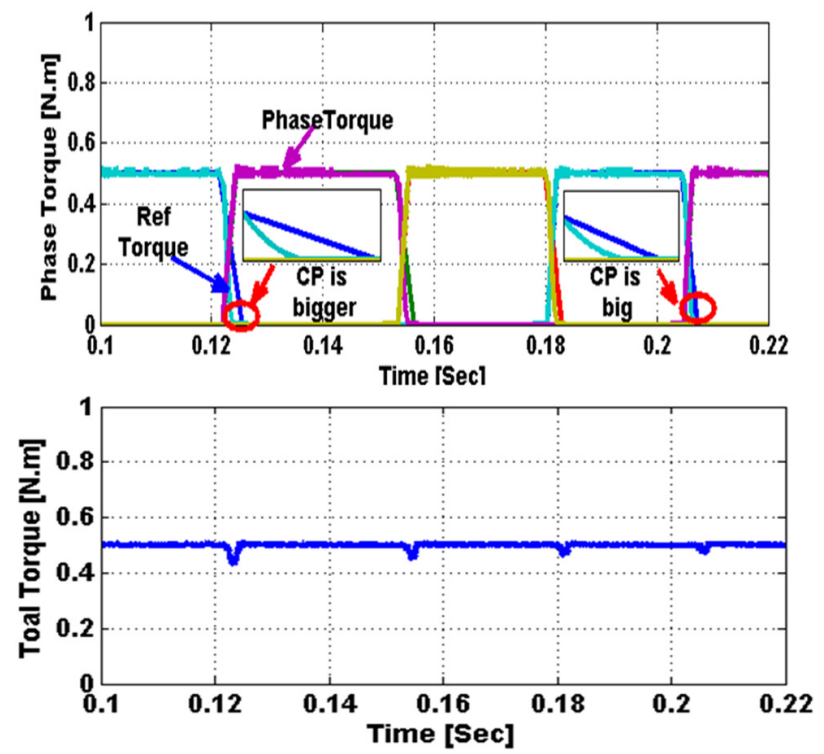

Fig. 10. The change in the torque during starting using the conventional TSF

Because the overlap angle depends on speed in the proposed method, the CP adjusts with motor speed changes. The change of the speed is exhibited by the change in the pulses width. The torque change during starting with the use of the proposed method is illustrated in Figure 11. It can be observed that the torque ripples are minimized by regulating the overlap angle and subsequently adjusting the CP. The overlap is $1.292^{\circ}$ at starting and reaches $2.607^{\circ}$ at the rated speed. Here it has to be confirmed that the phase torque response of the outgoing phase takes an exponential form, but it reaches in time the linear reference torque. 

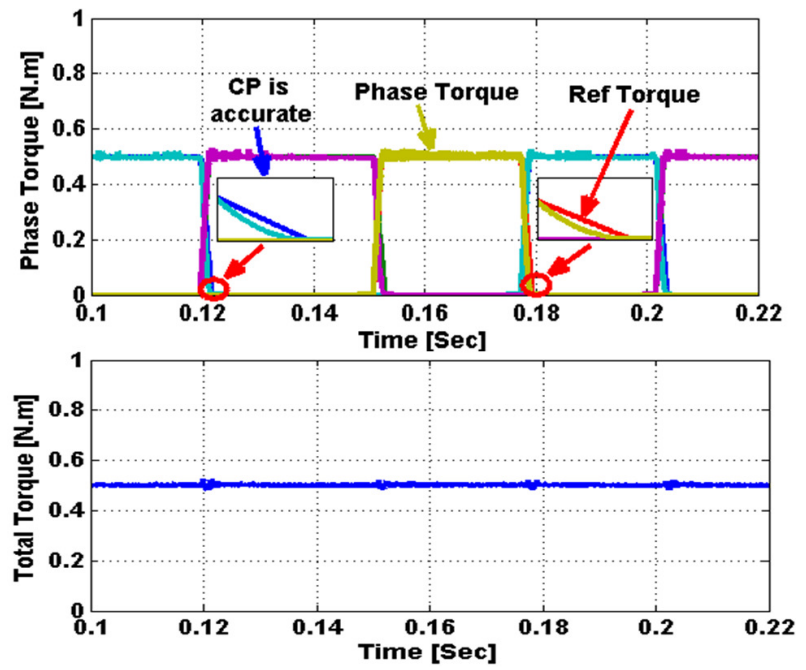

Fig. 11. The change in the torque during starting using the proposed TSF

\section{B. Speed Change Operation}

To check the effectiveness of the proposed method, the system is examined during the speed change above its rated value. The motor speed is increased by increasing the applied voltage with constant overlap angle at $2.5^{\circ}$. Figure 12 illustrates the change of the torque when the motor speed increases under the conventional TSF. It can be seen that the torque ripple is increased when the speed is increased and the CP become less than the period that the current requires to drop to zero. In the proposed method the overlap angle changes according to the motor speed and CP becomes accurate for commutation process. The change in the torque with exceeding speed over its rated value for the proposed TSF is shown in Figure13. The change of the speed from the change of the torque pulses width can be observed. The overlap angle has been changed from $2.607^{\circ}$ at rated speed to $3.023^{\circ}$ for speed equal to 1.3 of the rated speed. It can be seen that the torque ripples can be negligible.
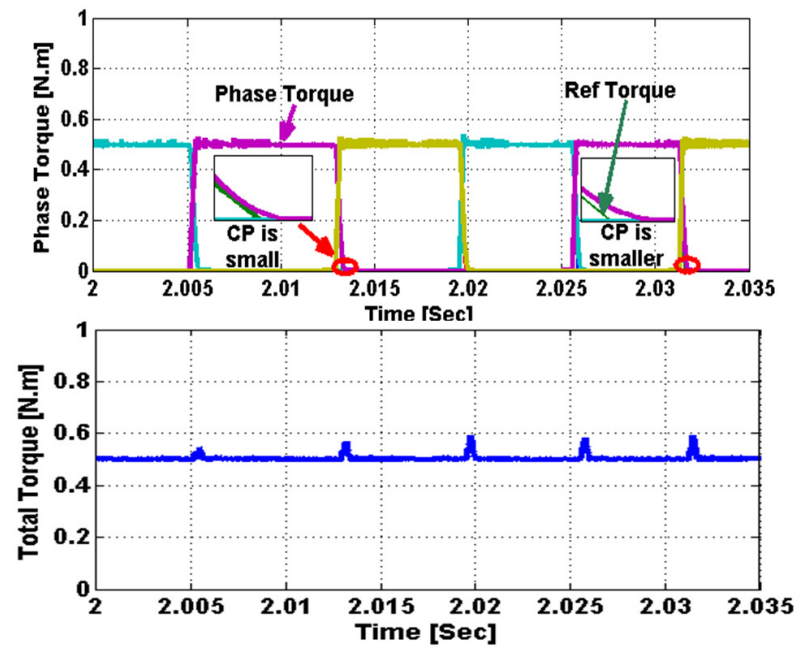

Fig. 12. The change of torque when the motor speed increases using the conventional TSF
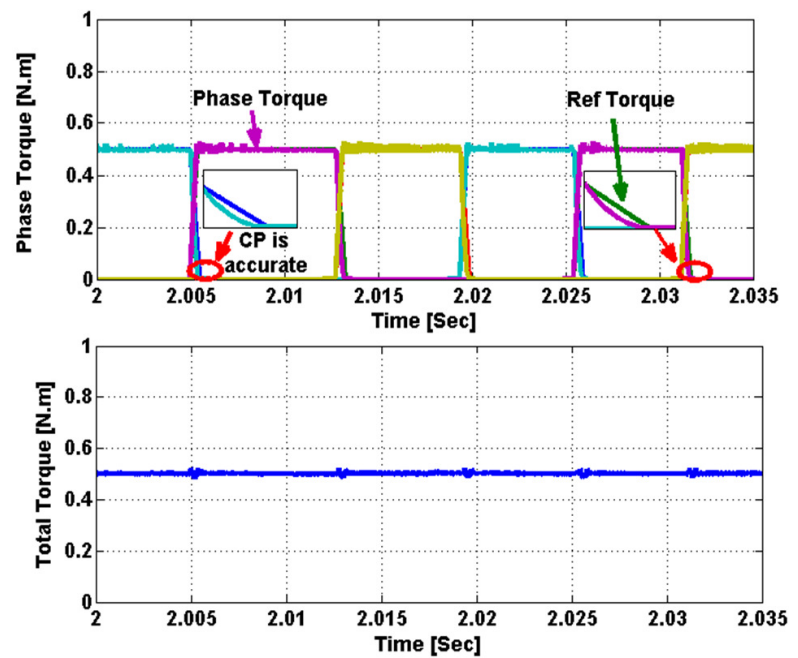

Fig. 13. The change of torque when the motor speed increases using the proposed TSF
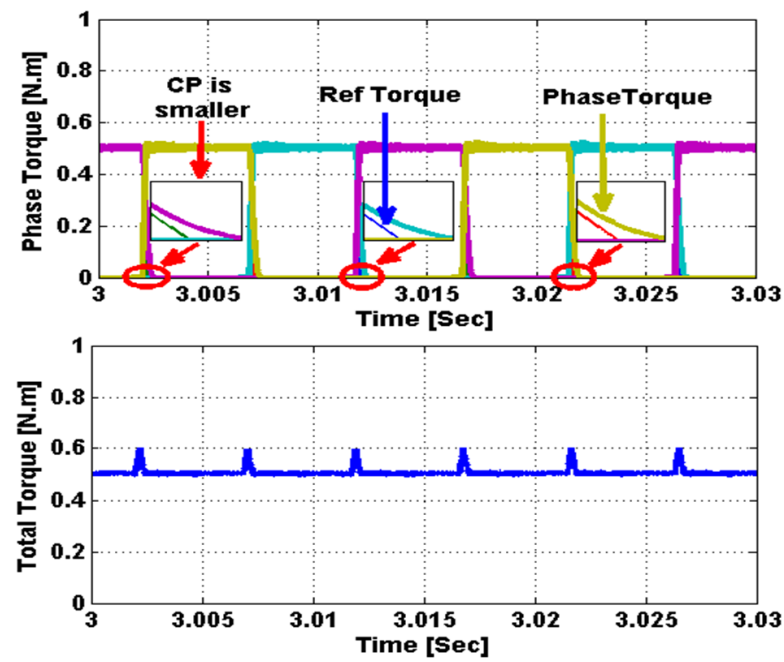

Fig. 14. The change of torque when the motor operates at high speed using the conventional TSF
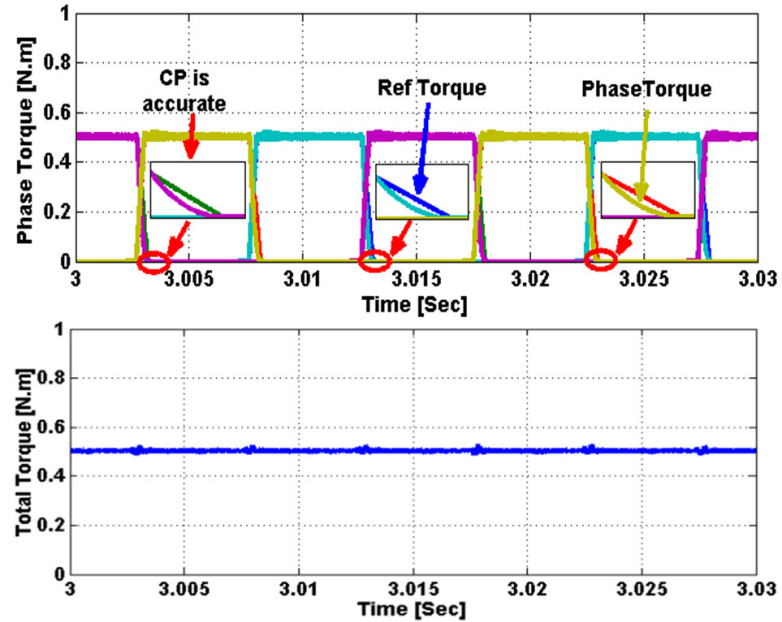

Fig. 15. The change of torque when the motor operates at high speed using the proposed TSF 


\section{Operation at High Speed}

Another case to examine the robustness of the proposed model is the operation at speed equal to 1.4 times the rated speed. It can be observed from Figure 14 that the torque ripples are very large when the motor operates at high speed under the conventional TSF with fixed overlap angle because the CP becomes smaller. On the contrary, the proposed method gives very good results at high speed as shown in Figure 15 because the $\mathrm{CP}$ is accurate along the torque pulses. Also, the overlap angle has been changed to $3.18^{\circ}$ for the new speed and has been kept constant because the speed is constant.

\section{CONCLUSION}

This paper has introduced a novel TSF technique for SRM torque ripple minimization, which reduces the torque ripple more efficient than traditional schemes. In the proposed technique the overlap angle in the TSF has been depended on the motor speed.

So, the CP has been accurately tuned to complete the commutation process for different speed operations. After this modification, the proposed method has been tested at various motor operating conditions. The results have been compared with those of the conventional TSF. The results showed that the proposed technique presents an effective method to improve the performance of a switched reluctance motor operating under torque ripple minimization for a wide speed range.

\section{REFERENCES}

[1] I. Husain, S. A. Hossain, "Modeling, simulation, and control of switched reluctance motor drives", IEEE Transactions on Industrial Electronics, Vol. 52, No. 6, pp. 1625-1634, 2005

[2] A. Mansouri, T. Hafedh, "Torque ripple minimization and performance investigation of an in-wheel permanent magnet motor", Engineering, Technology \& Applied Science Research, Vol. 6, No. 3, pp. 987-992, 2016

[3] E. Cetin, F. Daldaban, "Reducing torque ripples of the axial flux PM motors by magnet stepping and shifting", Engineering, Technology \& Applied Science Research, Vol. 8, No. 1, pp. 2385-2388, 2018

[4] I. Husain, M. Ehsani, "Torque ripple minimization in switched reluctance motor drives by PWM current control", IEEE Transactions on Power Electronics, Vol. 11, No. 1, pp. 83-88, 1996

[5] A. Xu, C. Shang, J. Chen, J. Zhu, L. Han, "A new control method based on DTC and MPC to reduce torque ripple in SRM", IEEE Access, Vol. 7, pp. 68584-68593, 2019

[6] R. Suryadevara, B. G. Fernandes, "Control techniques for torque ripple minimization in switched reluctance motor: An overview", IEEE $8^{\text {th }}$ International Conference on Industrial and Information Systems, Peradeniya, Sri Lanka, August 18-20, 2013

[7] X. Gao, X. Wang, Z. Li, Y. Zhou, "A review of torque ripple control strategies of switched reluctance motor", International Journal of Control and Automation, Vol. 8, No. 4, pp. 103-116, 2015

[8] E. Gouda, M. Hamouda, A. R. A. Amin, "Artificial intelligence based torque ripple minimization of switched reluctance motor drives", $18^{\text {th }}$ International Middle East Power Systems Conference, Cairo, Egypt, December 27-29, 2016

[9] F. Sahin, H. B. Ertan, K. Leblebicioglu, "Optimum geometry for torque ripple minimization of switched reluctance motors", IEEE Transactions on Energy Conversion, Vol. 15, No. 1, pp. 30-39, 2000

[10] H. Terzioglu, S. Herdem, B. A. L. Gungor, "The minimization of torque ripples of segmental type switched reluctance motor by Particle Swarm Optimization", International Journal of Intelligent Systems and Applications in Engineering, Special Issue, pp. 199-203, 2016
[11] H. Li, B. Bilgin, A. Emadi, "An improved torque sharing function for torque ripple reduction in switched reluctance machines", IEEE Transactions on Power Electronics, Vol. 34 , No. 2, pp. 1635-1644, 2019

[12] J. Ye, B. Bilgin, A. Emadi, "An offline torque sharing function for torque ripple reduction in switched reluctance motor drives", IEEE Transactions on Energy Conversion, Vol. 30, No. 2, pp. 726-735, 2015

[13] W. Peng, J. Gyselinc, J. W. Ahn, D. H. Lee, "Torque sharing function control of switched reluctance machines without phase current sensors", $21^{\text {st }}$ International Conference on Electrical Machines and Systems, Jeju, S. Korea, October 7-10, 2018

[14] X. D. Xue, K. W. E. Cheng, S. L. Ho, "Optimization and evaluation of torque-sharing functions for torque ripple minimization in switched reluctance motor drives", IEEE Transactions on Power Electronics, Vol. 24, No. 9, pp. 2076-2090, 2009

[15] Q. Sun, J. Wu, C. Gan, M. Shen, Y. Hu, "Investigation of direct torque control and torque sharing function strategy for switched reluctance motor applications", $18^{\text {th }}$ International Conference on Electric Machines and Machines, Pattaya City, Thailand, October 25-28, 2015

[16] Q. Sun, J. Wu, C. Gan, Y. Hu, J. Si, "OCTSF for torque ripple minimisation in SRMs", IET Power Electronics, Vol. 9, No. 14, pp. 2741-2750, 2016

[17] M. Hamouda, Q. Shafi Ullah, L. Szamel, "Compensation of switched reluctance motor torque ripple based on TSF strategy for electric vehicle applications", $4^{\text {th }}$ International Conference on Power Generation Systems and Renewable Energy Technologies, Islamabad, Pakistan, September 10-12, 2018

[18] R. Harikrishnan, F. M. Fernandez, "Improved online torque-sharingfunction based low ripple torque control of switched reluctance motor drives", IEEE International Conference on Power Electronics, Drives and Energy Systems, Trivandrum, India, December 14-17, 2016

[19] L. O. A. P. Henriques, L. G. B. Rolim, W. I. Suemitsu, P. J. C. Branco, J. A. Dente, "Torque ripple minimization in a switched reluctance drive by neuro-fuzzy compensation", IEEE Transactions on Magnetics, Vol. 36 , No. 5, pp. 3592-3594, 2000

[20] M. Dowlatshahi, S. M. S. Nejad, J. W. Ahn, "Torque ripple minimization of switched reluctance motor using modified torque sharing function", $21^{\text {st }}$ Iranian Conference on Electrical Engineering, Mashhad, Iran, May, 14-16, 2013

[21] T. Husain, A. Elrayyah, Y. Sozer, I. Husain, "Unified control for switched reluctance motors for wide speed operation", IEEE Transactions on Industrial Electronics, Vol. 66, No. 5, pp. 3401-3411, 2019

[22] H. S. Ro, K. G. Lee, J. S. Lee, H. G. Jeong, K. B. Lee, “Torque ripple minimization scheme using torque sharing function based fuzzy logic control for a switched reluctance motor", Journal of Electrical Engineering \& Technology, Vol. 9, No. 2, pp. 742-750, 2016 